\title{
Introduction to the Special Section on Clinical Approaches to Adolescents with Gender Dysphoria
}

\author{
Heino F. L. Meyer-Bahlburg ${ }^{1}$ \\ Published online: 9 August 2019 \\ (c) Springer Science+Business Media, LLC, part of Springer Nature 2019
}

\begin{abstract}
Transgender development in adolescents often occurs in the context of diverse psychiatric symptoms or diagnoses preceding, co-occurring with, or following the onset of the atypical gender identity variations. In addition, it tends to upset the prevailing binary gender ideology and, thereby, strain intra-family relationships as well as elicit stigma in other social contexts. The purpose of this Special Section is to describe clinical approaches to assessment and treatment of patients presenting with such challenging combinations of problems, before the background of societal changes that are affecting the traditional binary gender ideology.
\end{abstract}

Keywords Gender dysphoria $\cdot$ Gender identity variants $\cdot$ Transgender $\cdot$ Adolescence $\cdot$ Mental health

\section{Introduction}

The incidence of children and adolescents presenting with gender identity variants (GIVs) to mental health service providers has dramatically increased in recent decades (Zucker, 2017). This increase has coincided with diversification and fluidity of the spectrum of GIV presentations. Thus, individuals with GIVs are more frequently defining their gender in a non-binary fashion, using labels such as transgender, bigender, demigender, genderqueer, and many others. Expanded media exposure of persons with GIVs appears to facilitate their societal acceptance, at least in large urban centers. Moreover, the internet helps organizing and promoting transgender communities, which offer social support that may be lacking in a person's family. Yet, the growing fluidity of GIV presentations also poses challenges to gender clinicians. Medical and mental health providers often lack the training and education necessary to provide appropriate assessment and treatment services for transgender youth (Korpaisarn \& Safer, 2018; Rafferty et al., 2018), and this situation is exacerbated by the

Heino F. L. Meyer-Bahlburg

heino.meyer-bahlburg@ nyspi.columbia.edu

1 NYS Psychiatric Institute / Department of Psychiatry, Vagelos College of Physicians \& Surgeons of Columbia University, 1051 Riverside Drive, Unit 15, New York, NY 10032, USA recent and ongoing re-definitions of GIVs in diagnostic manuals and related controversies (Reed et al., 2016).

Concurrent psychiatric conditions, such as depression, anxiety, and autism, are disproportionately associated with transgender youth when compared with the general adolescent population and may intensify identity diffusion in general as well as gender-related dysphoria in particular (Reisner et al., 2015; van der Miesen, Hurley, \& de Vries, 2016). Psychiatric problems may reflect, in part, GIV-related stigma (Aparicio-García, DíazRamiro, Rubio-Valdehita, López-Núñez, \& García-Nieto, 2018; Gower et al., 2018). This complicates the task of practitioners to develop and implement effective clinical interventions for this population including recommendations regarding genderaffirming hormonal and surgical interventions, where indicated. GIVs forming in adolescence are particularly poorly understood (Kaltiala-Heino, Bergman, Työläjärvi, \& Frisén, 2018). Such a late emergence of a transgender identity — unforeseen in the absence of a preceding childhood history of overt gender nonconforming behavior-often jeopardizes the adolescents' relationship with their parents and other family members. Family therapy can play a crucial role in re-integrating adolescents with GIVs into the family and generating support from family members.

Reflecting the view of gender as a bimodal spectrum that accommodates a variety of gender identities between the two modes, male and female, the latest version of the Standards of Care (SOC-7) of the World Professional Association of Transgender Health (Coleman et al., 2011) re-defined the role 
of the mental health professional. The role changed from gatekeeping regarding the patient's access to cross-gender medical treatment to assisting the individual with GIV in exploring the various options of gender expression and identity and in determining their best fit to the individual, which may or may not include various hormonal and surgical treatments.

The idea for this Special Section originally arose from a Clinical Perspectives panel on this topic that was convened by Dr. Melina Sevlever and this author at the annual meeting of the American Academy of Child and Adolescent Psychiatry in New York City, October 24-29, 2016. A panel of five presenters, including one child and adolescent psychiatrist and four psychologists, all experienced in clinical interventions and research in this area, reviewed pertinent documents and data. A second child and adolescent psychiatrist, also a gender specialist, served as discussant. The original speakers except for one agreed to expand and update their reports and to contribute the resulting articles to this Special Section. As Dr. Erica Chin, who originally presented on family therapy, was unable to join this effort due to her taking on major new administrative responsibilities, another family therapist, Dr. Rachel Golden, agreed to take over from her. The task of editorial reviewing of this Special Section was shared by this author with the journal's Editor. Dr. Zucker reviewed this author's papers, this author reviewed Dr. Zucker's paper, and both reviewed the remaining ones.

The first article addresses five acute issues impacting GIVspecialized clinicians who work with adolescents. The second article examines late-onset GIVs in adolescents with preceding psychiatric conditions by way of two illustrative examples. It outlines a comprehensive multi-method and multi-informant approach to the assessment of GIVs on a consultant basis for patients who are in psychiatric treatment by other clinicians. The third article concerns the care of transgender youth with severe comorbid psychiatric conditions, including of patients in residential treatment settings. Case-based material is used to clarify the application of the standards of care related to the assessment and recommendations for gender-affirming hormonal and surgical interventions in such cases. The fourth article focuses on gender-affirming family-therapy techniques and demonstrates the usefulness of an intersectional approach, in view of the fact that individuals with GIVs and their families may hold many diverse social identities. The fifth article focuses on the ongoing controversy regarding the classification of GIVs as mental illness and lays out pertinent implications of the major societal changes that undercut the traditional division of labor between the binary sexes.

While the nosological categorization of gender atypicalities is in flux, clinicians need to be familiar with the major positions and associated concerns so as to be able to discuss them with the respective patients and their families. In addition, clinicians must be aware of the common clinical challenges in the care of transgender youth, that is, accommodate emerging and often fluid gender identities, while also managing psychiatric comorbidities and changing family dynamics towards support for the adolescent.

\section{Compliance with Ethical Standards}

Conflict of interest The author declares that he has no conflict of interest.

Human and Animal Rights This article does not contain any studies with human participants or animals performed by the author.

\section{References}

Aparicio-García, M. E., Díaz-Ramiro, E. M., Rubio-Valdehita, S., López-Núñez, M. I., \& García-Nieto, I. (2018). Health and wellbeing of cis-gender, transgender and non-binary young people. International Journal of Environmental Research and Public Health, 15(10), 2133. https://doi.org/10.3390/ijerph15102133.

Coleman, E., Bockting, W., Botzer, M., Cohen-Kettenis, P., DeCuypere, G., Feldman, J., ... Zucker, K. (2011). Standards of care for the health of transsexual, transgender, and gender-nonconforming people, Version 7. International Journal of Transgenderism, 13, $165-232$.

Gower, A. L., Rider, G. N., Coleman, E., Brown, C., McMorris, B. J., \& Eisenberg, M. E. (2018). Perceived gender presentation among transgender and gender diverse youth: Approaches to analysis and associations with bullying victimization and emotional distress. LGBT Health, 5, 312-319.

Kaltiala-Heino, R., Bergman, H., Työläjärvi, M., \& Frisén, L. (2018). Gender dysphoria in adolescence: Current perspectives. Adolescent Health, Medicine and Therapeutics, 9, 31-41.

Korpaisarn, S., \& Safer, J. D. (2018). Gaps in transgender medical education among healthcare providers: A major barrier to care for transgender persons. Reviews in Endocrine and Metabolic Disorders, 19, 271-275. https://doi.org/10.1007/s11154-018-9452-5.

Rafferty, J., Committee on Psychosocial Aspects of Child and Family Health, Committee on Adolescence, \& Section on Lesbian, Gay, Bisexual and Transgender Health and Wellness. (2018). Ensuring comprehensive care and support for transgender and genderdiverse children and adolescents. Pediatrics, 142(4), 20182162. https://doi.org/10.1542/peds.2018-2162.

Reed, G. M., Drescher, J., Krueger, R. B., Atalla, E., Cochran, S. D., First, M. B., ... Saxena, S. (2016). Disorders related to sexuality and gender identity in the ICD-11: Revising the ICD-10 classification based on current scientific evidence, best clinical practices, and human rights considerations. World Psychiatry, 15, 205-221. https://doi.org/10.1002/wps.20354.

Reisner, S. L., Vetters, R., Leclerc, M., Zaslow, S., Wolfrum, S., Shumer, D., \& Mimiaga, M. J. (2015). Mental health of transgender youth in care at an adolescent urban community health center: A matched retrospective cohort study. Journal of Adolescent Health, 56, 274-279.

van der Miesen, A. I., Hurley, H., \& de Vries, A. L. C. (2016). Gender dysphoria and autism spectrum disorder: A narrative review. International Review of Psychiatry, 28, 70-80. https://doi. org/10.3109/09540261.2015.1111199.

Zucker, K. J. (2017). Epidemiology of gender dysphoria and transgender identity. Sexual Health, 14, 404-411.

Publisher's Note Springer Nature remains neutral with regard to jurisdictional claims in published maps and institutional affiliations. 